\title{
The performance of technical trading rules in Socially Responsible Investments
}

\section{Article}

\section{Accepted Version}

Creative Commons: Attribution-Noncommercial-No Derivative Works 4.0

Urquhart, A. and Zhang, H. (2019) The performance of technical trading rules in Socially Responsible Investments. International Review of Economics and Finance, 63. pp. 397411. ISSN 1059-0560 doi: https://doi.org/10.1016/j.iref.2019.05.002 Available at https://centaur.reading.ac.uk/83820/

It is advisable to refer to the publisher's version if you intend to cite from the work. See Guidance on citing.

To link to this article DOI: http://dx.doi.org/10.1016/j.iref.2019.05.002

Publisher: Elsevier

All outputs in CentAUR are protected by Intellectual Property Rights law, including copyright law. Copyright and IPR is retained by the creators or other copyright holders. Terms and conditions for use of this material are defined in the End User Agreement.

\section{www.reading.ac.uk/centaur}

\section{CentAUR}

Central Archive at the University of Reading 
Reading's research outputs online 


\title{
The Performance of Technical Trading Rules in Socially Responsible Investments
}

\begin{abstract}
This study is the first to examine the performance of technical trading in tradeable Socially Responsible Investment (SRI) indices. We employ a number of popular trend-following and meanreverting technical trading rules and find that trend-following technical trading rules offer very little predictive power or significant returns to investors. However the mean-reverting technical trading rules do offer significant returns, even after controlling for data-snooping, risk, transaction costs and out-of-sample testing. Therefore our results add to the literature by showing that meanreverting technical trading rules offer substantial predictive power in SRI indices, but traditional trend-following rules offer very little predictive power.

Keywords: Socially Responsible Investments; Technical Analysis; Data-Snooping

JEL Codes: G1; G11
\end{abstract}




\section{Introduction}

Socially responsible investments (SRI) are investments based on governance, environmental and social criteria and thereby excluding investments in firms that pollute the environment, sell alcohol, tobacco and weapons, as well as firms that have poor governance. They are distinct from conventional funds and are not conventional funds in disguise, as demonstrated by Kempf and Osthoff (2008). SRI investments have grown substantially, especially in the UK where the SRI fund industry continues to grow significantly, and out-pacing the global investment growth. In 2016, more than a fifth of all capital under professional management in the United States was invested in SRI funds. ${ }^{1}$ This type of investing is highly international, with nearly $40 \%$ of the 5.5 trillion of assets under management from oversea investors. ${ }^{2}$ SRI ratings are important for investors as demonstrated by Cellier et al. (2016), who show a decrease in trades prior to announcements, followed by a rise afterwards, indicating that investors care about announcements of extrafinancial ratings. Furthermore, Ammann et al. (2018) show that the Morningstar Sustainability Rating has a huge impact on mutual fund flows, where in the first year after publication, higherrated funds receive between $\$ 4.1 \mathrm{~m}$ and $\$ 10.1 \mathrm{~m}$ higher net flows while lowrated funds receive between $\$ 1.0 \mathrm{~m}$ to $\$ 5.0 \mathrm{~m}$ lower net flows than averagerated funds. Also, Kim et al. (2018) note that investors are attracted more to firms with higher CSR ratings. Therefore SRI stocks and funds are substantially different to conventional funds.

Given the importance and sheer size of the SRI sector, there have been a number of papers examining the performance of SRI funds with conventional funds and whether investing in SRI stocks outperform non-SRI stocks, although the results remain inconclusive. For instance, there is evidence that stocks with high SRI ratings outperform traditional stocks (Kempf and Osthoff (2007); Chan and Walter (2014)) while some studies have found no significant difference (Statman and Glushkov (2009); Humphrey and Tan (2014)). There is evidence that SRI funds do outperform traditional funds (Gil-Bazo et al. (2010); Ooi and Lajbcygier (2013); Nofsinger and Varma (2014); Muñoz et al. (2014)), while there is contradictory evidence that they under-perform traditional funds (Jones et al. (2008); Leite and Cortez (2015)), while there is also evidence that there is no significant under- or over-performance between SRI funds and conventional funds (Cummings (2000); Bauer et al. (2005); Gregory and Whittaker (2008); Bello (2005); Kreander et al. (2005);

\footnotetext{
${ }^{1}$ The Forum for Sustainable Responsible Investment at https://www .ussif .org/trends.

${ }^{2}$ See http://www. eurosif.org/sri-study-2016/united-kingdom/.
} 
Benson et al. (2006); Bauer et al. (2007) Fernandez-Izquierdo and Matallin-Saez (2008); Derwall and Koedijk (2009); Climent and Soriano (2011); Humphrey et al. (2016)). Recently, Oikonomou et al. (2018) form SRI portfolios and show for SRI portfolios, investors should employ more formal optimization approaches (such as Markowitz, Black-Litterman and robust estimation) since they generate superior returns compared to more simplistic optimization approaches (such as naïve diversification, risk parity and reward-to-risk).

A small body of research has examined the performance of SRI indices, such as the FTSE4Good Index, which provides a SRI investment universe for various regions around the world and are tradable indices. Studying indices may be more appropriate since investors are likely to hold portfolios of SRI stocks to benefit from diversification than just hold a few SRI stocks. Statman (2006) shows that SRI indices outperformed the S\&P500 during the late 1990s but did worse than the S\&P500 during the early 2000s while Schroder (2007) shows that there is no difference in performance between SRI and conventional indices. Consolandi et al. (2009) shows that the Dow Jones Sustainability Stoxx Index (DJSSI) slightly outperforms the benchmarks. Belghitar et al. (2014) examine the performance of FTSE4Good indices and find that there is a price to paid for social responsible investing in these indices while Brzeszczyński and McIntosh (2014) show that UK SRI portfolio returns are greater than the FTSE100. ${ }^{3}$

An area that remains unexplored is whether active trading in SRI generates higher returns than trading in conventional investments. One popular type of active trading that has received a lot of attention in industry as well as the academic literature is technical trading, which uses past price information to determine future prices through trend analysis. Practitioners have been found to use technical analysis extensively, with Smith et al. (2016) showing that $21.6 \%$ of live hedge funds use technical analysis while Menkhoff (2007) reports that technical analysis is widespread in the foreign exchange market. Within the academic literature, the seminal paper by Brock et al. (1992) finds technical trading generates significant predictability over 90 years in the DJIA, with Bessembinder and Chan (1998), Sullivan et al. (1999) and White (2000) supporting the findings and showing that the results of Brock et al. (1992) are not due to data-snooping. Significant findings have also been found in equity markets by Hsu et al. (2010), Shynkevich (2012), Han et al. (2013) and Neely et al. (2014), commodity futures markets by Szakmary et al. (2010), Narayan et al.

\footnotetext{
${ }^{3}$ For a thorough review of the burgeoning literature on environmental, social and governance disclosures and performance and their effects on firm value, see Brooks and Oikonomou (2018).
} 
(2015), and Han et al. (2016)), in currency markets by Neely et al. (1997), Qi and Wu (2006), Neely et al. (2009), Hsu et al. (2016) and Zarrabi et al. (2017) and recently in bond markets by Shynkevich (2016). ${ }^{4}$

Given the importance and size of the SRI industry, as well as the vast literature examining the predictability and profitability of technical trading rules, this paper performs a comprehensive examination of the performance of technical trading rules in SRI indices. We consider three tradeable FTSE4Good Index series which consist of stocks that meet their SRI standards. Specially, we examine the FTSE4Good US, FTSE4Good UK and FTSE4Good Europe indices to determine whether ethical traders should apply technical analysis to SRI stocks. We consider eight different technical rules with a range of different parameters to order to avoid the issue of choosing too few rules that can cause bias in the statistical inference due to data mining Shynkevich (2012). However contrary to previous studies, we split the technical trading rules into two main groups, namely trend-following and mean-reversal rules. Trend-following rules aim to predict and follow the trend of the market while reversal rules attempt to predict when a reversal in price is occurring. Most technical trading studies bunch trend-following and reversal rules together but they are quite different and both try to predict different behaviors of the market. Therefore they may be picking up different properties of the markets which may be masked by grouping the both types together. We employ a range of performance metrics, including risk-adjusted measures as well as breakeven costs to determine the success of the technical trading rules. To safeguard against data-snooping, we generate individual bootstrapped $p$-values of each technical trading by comparing the actual $p$-value to 1,000 stationary bootstrapped $p$-values following the method of Sullivan et al. (1999). We then use these individual bootstrapped $p$-values and adopt a number of approaches to control for multiple hypothesis testing, namely the family-wise error rate (FWER) and the false discovery rate (FDR). ${ }^{5}$ Our results show that in general, trend-following strategies do not generate significant returns for investors, while a much larger proportion of mean-reversion rules do report significant returns. This is supported by various risk-adjusted measures, the breakeven transaction costs and multiple hypothesis adjustments to the bootstrapped $p$-values. To add further robustness to our analysis, we conduct an out-of-sample analysis and show that the vast majority of trend-following

\footnotetext{
${ }^{4}$ See Park and Irwin (2007) for a review of the literature of technical trading rules up to 2007 while Batten et al. (2018) provide a recent review of the literature in intraday technical trading.

${ }^{5}$ Harvey and Liu (2014) provide a detailed discussion of the issue and importance of multiple hypothesis testing.
} 
rules fail to generate significant in-sample returns. However the mean-reversion rules that generate in-sample significant returns generate positive out-of-sample returns and positive Sharpe ratios, indicating that the mean-reversion rules are not due to data-mining and that investors could have gained positive returns from implementing these types of technical trading rules. Therefore our results suggest that technical traders should consider employing mean reverting technical trading rules to SRI stocks.

Therefore, this paper offers a number of important contributions to the literature. First, this is the paper to our knowledge that examines the performance of technical trading in SRI tradeable indices. Lots of studies have examined portfolio implications of SRIs and also the performance of technical trading rules in many other markets, but no study has investigated whether technical trading rules offer predictive power in an SRI setting. Second, we separate our technical trading rules into two main categories, namely trend-following technical trading rules and mean-reverting technical trading rules. We do this since trend-following rules attempt to follow market movements while mean-reverting rules attempt to time when a market reversal is imminent, so they are contrasting strategies. Our third main contribution is that we comprehensively safeguard against data-snooping by implementing bootstrapped p-values of Sullivan et al. (1999) and then control for multiple hypothesis testing through the family-wise error rate (FWER) and false discovery rate (FDR). Fourth, instead of estimating transaction costs for investor, we calculate breakeven transaction costs. Transaction costs may be significantly different depending if the investor is a retail or institutional investor and therefore arbitrarily choosing transaction costs may not be appropriate. Breakeven transaction costs however report the value transaction costs need to be so that the profits from trading are zero and therefore provides an opportunity cost value for implementing these trading rules. Finally, to safeguard against data-snooping, we employ out-ofsample estimation where we choose the best performing rules in an in-sample period and report their performance in the out-of-sample period.

The rest of the paper is organized as follows. Section 2 sets out the various technical trading rules that we implement while Section 3 explains the data employed in this study. Section 4 outlines the various performance metrics considered in order to assess the performance of our rules while section 5 outlines the data-snooping procedure implemented. Section 6 reports the empirical results while Section 7 provides a summary and the conclusion. 


\section{Technical Trading Rules}

Taylor and Allen (1992) note that technical analysis can be separated into two distinct categories, namely the qualitative form and the quantitative form. The qualitative form is where charts are analyzed and attempts are made to identify patterns in the data while the quantitative form is the analysis of past charts through time-series analysis to construct trading signals. The main difference is that, given a certain trading rule, quantitative technical analysis is completely objective and every individual should come to the same conclusion while qualitative technical analysis is subjective and individuals may come to different conclusions from the same chart. Many previous studies on quantitative technical trading rules pool lots of different technical trading rules together and report how many rules outperform in- and out-of-sample via annualized returns and various risk-adjusted measures. However pooling these technical trading rules together can be misleading as some technical trading rules attempt to follow the market trend while some attempt to indicate upcoming reversals. Therefore the rationale of trend-following rules are generally the same, while the rationale behind mean-reversion rules are generally the same. They both aim at capturing different aspects of the market and therefore we differentiate popular technical trading rules into two broad categories, namely "trend-following rules" and "reversal rules".

We define trend-following rules as ones which provide signals of the continued direction of the current market trend. That is, these rules attempt to identify trends in the market and follow these trends in the future. Most of the well-known and previously studied technical trading rules are trend-following rules and we examine six of the most popular. The first trend-following rule is the moving average rule (which is the most examined class of technical trading rule in the literature) which attempts to benefit from trends in the data as well as identify imminent reversals by examining moving averages. The second rule is the exponential moving average rule, which is identical to the moving average rule but the previous periods prices are not calculated through a simple average but through an exponentially-weight average. The third trend-following rule we study is the weighted moving average rule, which again is identical to the moving average rule but previous periods prices are are not calculated through a simple average, but through a linear weighted average.

The fourth trend-following rule we study are filter rules which measure and follow trends by buying (selling) when the price has increased (decreased) by a given percentage. The fifth are support-resistance trading rules, which create support or resistance bounds around the price which 
if they breach, indicates further movement in the same direction. The sixth trend-following rule is the channel breakout rules which generate support and resistance levels which, once breached, indicate further movement in the same direction. All of these rules attempt to follow a trend that hopes to gain excess returns.

Reversal rules on the other-hand attempt to identify future market reversals. That is, they attempt to predict moments in time when a reversal is approaching and therefore recommends selling (buying) if the rule believes the market is in an overbought (oversold) zone. Reversal rules are less popular in the literature than trend-following rules which may be due to the previous success of trend-following rules and the lack of reporting of negative results in the literature. ${ }^{6}$ Three reversal rules are studied where the first is the popular relative strength index (RSI) of Wilder (1978) which measures the overall strength of the price by generating a ratio of upward price movement to total price movement. The second reversal rule we study is the Aroon indicator, proposed by Tushar Change in 1995, is a technical trading rule used for identifying the likelihood that a trend will reverse. The third reversal rule we employ is Bollinger Bands, created by John Bollinger, which provides a relative high and low band and if the price falls outside the bands, this signals a market change.

The choice of parameters to employ is quite important since different parameters may generate quite contrasting returns. Therefore we examine a number of different parameters of each class of trading rule, and therefore obtain a very large number of different possible rules. Specifically, we employ the exact same technical trading rules and parameters as the recent paper by Hsu et al. $(2016){ }^{7}$

\section{Data}

In this paper, we employ FTSE4Good data which are tradeable indices which have an advisory committee who decide which firms are included, based on their responsibility. We select three of the most popular FTSE4Good series, namely the FTSE4Good-US 100, the FTSE4Good-UK 50 and the FTSE4Good-Europe 50, which each provide indices based on firms in the US, the UK and European markets respectively.

\footnotetext{
${ }^{6}$ For an interesting study on the lack of negative results in the scientific literature, see Fanelli (2012).

${ }^{7}$ For more details on these rules and the exact parameters, we refer the reader to the appendix and Hsu et al. (2016).
} 
We collect daily data from Datastream for all the indices and we also collect daily risk-free rates in the currency that matches the currency of the indices. ${ }^{8}$ We study the period 1st January 2002 to 31st December 2017 which provides 16 full years of data. ${ }^{9}$ We calculate daily returns for each index by:

$$
r_{i, t}=\frac{P_{i, t}}{P_{i, t-1}}-1
$$

where $r_{i, t}$ is the return for index $i$ on day $t$ while $P_{i, t}$ is the closing price on day $t$ and $P_{i, t-1}$ is the closing price of index $i$ on day $t-1$. Table 1 provides descriptive statistics of all indices examined in this paper where all indices have a positive mean return, with the FTSE4Good US having the largest mean return. FTSE4Good Europe has the highest standard deviation of return while the FTSE4Good UK has the lowest. All return series exhibit positive skewness while all exhibit excess kurtosis, indicating a leptokurtic distribution of returns.

\section{Performance Metrics}

The return from the $j^{\text {th }}$ technical trading in each index is defined as;

$$
R_{j, t}=S_{j, t-1} r_{t}
$$

where $S_{j, t-1}$ is the position suggested by the $j^{\text {th }}$ technical trading rule which is determined by historic prices. $S_{j, t-1}$ either takes the value of 1 where we go long in the SRI, -1 where we go short in the SRI or 0 where we are neutral. If we are neutral, we are out of the market and invested in cash. ${ }^{10}$

Any analysis of trading strategies needs to be concerned with transaction costs since if the returns from a trading strategy are not positive after taking account of transaction costs, the strategy is worthless to an investor. This is especially important since some papers have found that technical trading rules are profitable for investors but once transaction costs are accounted

\footnotetext{
${ }^{8}$ The risk-free rate is required for performance evaluation to calculate the excess returns of the technical trading rules.

${ }^{9}$ FTSE4Good indices were launched in July 2001 and our data begins in January 2002 to avoid a lack of trading volume when it was first launched and to enable 16 full years of data with removes any seasonality effects.

${ }^{10}$ We invest in cash if we are not long or short in the SRI, meaning our results are based purely on the benefits of employing technical analysis on SRI since we take no returns from the risk-free rate.
} 
for, many rules are no longer profitable. There is always a debate as the magnitude of transaction costs, especially between retail and institutional investors. Therefore we report the breakeven transaction costs in order to determine the magnitude of transaction costs that would make the returns from technical trading zero. In this way, there is no bias in our estimation of transaction costs and a trader can then determine whether employing technical trading rules in SRI indices would be profitable for them.

The first performance metric we report is the daily mean return of the $j^{\text {th }}$ technical trading rule which is defined as;

$$
\bar{R}_{j}=\frac{1}{T} \sum_{t=1}^{T} R_{j, t}
$$

where $\bar{R}_{j}$ is the mean return. This is the simplest performance measure and quantifies the average return from each trade of each technical trading rule. However, an issue with this measure is that the risk of the strategy is not accounted for in terms of volatility. Therefore we also calculate the Sharpe ratio which is very popular in the finance industry. The Sharpe ratio measures the average excess return per unit of risk, where risk is calculated as the standard deviation of excess returns. The Sharpe ratio of the $j^{\text {th }}$ technical trading rule is defined as;

$$
S R_{j}=\frac{\bar{R}_{j}-r_{f}}{\sigma_{j}}
$$

where $r_{f}$ is the daily risk free-rate obtained from the Kenneth French data library and $\sigma_{j}$ is the standard deviation of excess returns. ${ }^{11}$ However an issue with the Sharpe ratio is that it includes downside volatility as well as upside volatility, with the same weighting. Investors may only be interested in the downside risk as the upside provides them with greater returns. Consequently we also calculate the Sortino ratio which of the $j^{\text {th }}$ technical trading rue is defined as;

$$
S O_{j}=\frac{\bar{R}_{j}-r_{f}}{\sigma_{n, j}}
$$

where $\sigma_{n, j}$ is the standard deviation of negative excess returns generated by the $j^{\text {th }}$ trading rule and again we annualized the Sortino ratio. Our final performance metric is the Calmar ratio, which is an important indicator for investment banks as well as the hedge fund industry (Psaradellis

\footnotetext{
${ }^{11}$ Kenneth French data sets can be found at http://mba.tuck.dartmouth.edu/pages/faculty/ken.french/ data_library.html.
} 
et al. (2017)). ${ }^{12}$ The Calmar ratio calculates the average annual return of an investment per unit of maximum drawdown and is especially useful for practitioners who employ momentum strategies that can suffer considerable drawdowns. The Calmar ratio of the $j^{\text {th }}$ technical trading rue is defined as;

$$
C R_{j}=\frac{\bar{R}_{j}}{M D D_{j}}
$$

where $M D D_{j}$ is the maximum drawdown of the excess returns generated by the $j^{\text {th }}$ trading rule.

\section{Data-Snooping}

Data snooping bias is a real issue whenever any trading strategy is implemented since examining just the mean excess return across rules is not sufficient. Searching among a range of competing trading rules means more and more hypotheses being tested, as badly performing rules are disregarded. The problem of multiple hypothesis testing is that if we increase the number of hypotheses tested, there is a higher likelihood of a rare event and hence incorrectly rejecting the null hypothesis (Type I error). In our case, after testing $n$ number of trading rules, a skeptic would argue that they would have expected at least one rule to perform well. ${ }^{13}$ This is demonstrated by Chordia et al. (2018) who create 2.1 million trading strategies and apply various multiple hypothesis testing techniques to show that the outperformance of single hypothesis testing are false. The surviving strategies have no theoretical underpinnings and therefore $p$-hacking is an issue and after correcting for it, successful strategies are quite rare.

We adopt two broad approaches to deal with multiple hypothesis testing, namely family-wise error rate (FWER) and the false discovery rate (FDR).

\subsection{FWER}

The strictest multiple hypothesis test is to avoid any false rejections and control for the FWER, which is defined as the probability of rejecting even one of the true null hypothesis. Hence the FWER captures the probability of one false discovery. We implement two main FWER tests.

\footnotetext{
${ }^{12}$ The Calmar ratio was developed by Young (1991) and stands for California Managed Account Reports.

${ }^{13}$ Or as Economics Nobel Laureate Ronald Coase put it, "if you torture the data long enough, it'll confess to anything".
} 


\subsubsection{Bonferroni Method}

The Bonferroni method is a single-step procedure, where all the $p$-values are compared to a single critical value. The critical $p$-value is $\alpha / M$, where $\alpha$ is the critical value chosen and $M$ is number of rules examined. The lack of power is due to the fact that is treats all test statistics as independent and therefore ignores cross-correlation that is bound to be present in the technical trading rules employed in this study.

\subsubsection{Holm Method}

The Holm method is a stepwise adjustment that rejects the null hypothesis of no outperforming rules if $p_{i} \leq \alpha /(M-i+1)$ for $i=1, \ldots m$. The Holm method becomes less strict than the Bonferroni method for large $p$-values hence the Holm method rejects more hypotheses. However one issue is that it does not consider the dependence structure of the individual $p$-values.

\subsection{FDR}

An alternative multiple hypothesis procedure is the False Discovery Rate (FDR). FDR measures the expected false discovery proportion among all strategies where a multiple hypothesis testing method is said to control FDR at level $\delta$ if $F D R \equiv E(F D P) \leq \delta$, where the level $\delta$ is user-defined.

\subsubsection{BH Method}

One of the earliest FDR controlling methods is by Benjamini and Hochberg (1995) and is a stepwise procedure that insists that all $p$-values are ranked from smallest to largest such that:

$$
j^{*}=\max \left\{j: p \leq \frac{j \times \delta}{M}\right\}
$$

Where we reject all hypothesis $H_{1}, H_{2}, \ldots, H_{j}$.

\subsubsection{BY Method}

A general control for FDR was introduced by Benjamini and Yekutieli (2001) by replacing the definition of $j^{*}$ with:

$$
j^{*}=\max \left\{j: p \leq \frac{j \times \delta}{M \times C_{M}}\right\}
$$

where the constant $C_{M}=\sum_{i=1}^{M} 1 / i \approx \log (M)+0.5$. However this method is less power than the $B H$ method and is still very conservative. 
We employ these four multiple hypothesis testing procedures on the individual $p$-values of each trading rule. Consistent with Bajgrowicz and Scaillet (2012), to acquire individual p-values, we follow the re-sampling procedure of Sullivan et al. (1999). We employ the stationary bootstrap method of Politis and Romano (1994) to resample the returns of each strategy, where the corresponding test statistic for each bootstrap series of returns is calculated by comparing the original $p$-value with the bootstrapped $p$-values. ${ }^{14}$

\section{Empirical Results}

\subsection{Initial Results}

This section reports the empirical results of our technical trading rules applied to FTSE4Good indices. ${ }^{15}$ Table 2 presents the average rules for all technical trading rules for all three FTSE4Good indices examined where we show that the average buy return from the technical trading rules is positive for the FTSE4Good US, but negative for the FTSE4Good UK and FTSE4Good Europe. All indices report a negative average sell return while the average overall return is negative for all indices. All indices report negative average Sharpe, Sortino and Calmar ratios indicating that these technical trading rules generate, on average, no positive returns or risk-adjusted returns for investors.

Table 2 reports the average performance of the technical technical rules, but this may mask some of the performance of the technical trading rules. For instance if a couple of technical trading rules generate large negative returns, this will have a large detrimental effect on the average performance reported in Table 2. Also, investors are unlikely to employ all the parameters of each rules and therefore Table 3 reports the percentage of technical trading rules that report positive returns, significant positive returns, and positive Sharpe ratios. ${ }^{16}$ For the FTSE4Good US, 30.44\% of rules generate positive returns, while $3.03 \%$ of all rules generate positive significant returns, while $21.30 \%$ report positive Sharpe ratios. We also find that $16.79 \%$ and $29.71 \%$ of technical trading rules for

\footnotetext{
14 The block length is equal to 0.1 and the number of bootstrap realizations is set to 1000 , consistent with previous studies.

${ }^{15}$ Throughout our results section, we report a summary of the results since it is impossible to provide the results for every single trading rule. However the performance of all of the individual technical trading rules are available upon request from the corresponding author.

${ }^{16}$ As noted before, the number of positive Sharpe, Sortino and Calmar ratios will be the same and therefore we only report the number of positive Sharpe ratios for brevity.
} 
the FTSE4Good UK and FTSE4Good Europe generate positive returns for investors, while $1.71 \%$ of the positive rules are statistically significant. Therefore our results in Table 3 show that a good proportion of our technical trading rules generate positive returns, but less than $5 \%$ of the them generate significant returns. However for each index, a substantial proportion of rules generate positive Sharpe ratios which may be of more interest to investors than the statistical significance of the returns.

\subsection{Trend Following vs Mean Reversion}

As noted earlier, technical trading rules in general take two forms: trend following rules and mean reversion rules. These two groups of rules attempt to capture complete opposite behavior in the market and therefore putting them into one basket and examining the performance of them may mask the fact that one group of these rules may be significantly outperforming the other. Therefore in Table 4 we report the average returns for all the technical rules that we group as trend following in Panel A, and those rules that are mean reversion rules in Panel B. We can see that for the FTSE4Good US, FTSE4Good UK and FTSE4Good Europe, the average return is positive for the mean reversion rules, but negative for the trend following rules. This suggests that for these indices, trend following rules on average do not generate positive returns for investors, while mean reversion rules do. Similar to before, studying the average performance may mask some of the findings and therefore in Table 5 we report the percentage of positive returns, significant returns and positive Sharpe ratios for the trend following rules and mean reversion rules separately. We find that only $23.72 \%, 9.51 \%$ and $23.66 \%$ of technical trading rules for each index reports positive returns for trend-following rules, while $68.38 \%, 56.39 \%$ and $63.62 \%$ report positive returns for mean-reversion rules. Therefore it seems that mean reversion rules do produce substantially more positive returns than trend following rules. This is also reported in the percentage of significant rules, where no trend following technical trading rules generate significant returns for the FTSE4Good US and FTSE4Good UK, while $20.16 \%$ and $10.98 \%$ rules mean reversion rules generate significant returns. This is also reflected in the percentage of positive Sharpe ratios where substantially more mean reversion rules report positive Sharpe ratios compared to trend following rules.

Therefore our analysis indicates that that the mean-reversion technical trading rules do offer much higher risk-adjusted returns to the trend-following rules. This suggests that investors of SRI funds should employ mean-reverting rules, rather than trend-following rules when employing technical trading in investment strategies. 


\subsection{Robustness}

In this section, we perform some robustness analysis to our previous results to confirm our previous findings and add more validity to our results.

\subsubsection{Breakeven Transaction Costs}

Up to this point, our analysis has assumed zero transaction costs but in practice these may be significant. A technical trading rule may generate significant returns, but these returns may be wiped out when transaction costs are adjusted for (Timmermann and Granger (2004)). We report in Table 6 the average number of trades that the trend following and mean reversion rules generate, and the breakeven transaction costs. That is, the magnitude the transactions need to be to render the overall return of the technical trading rule zero. We also report the percentage of technical trading rules that generate breakeven transaction costs greater than 50 basis points, which is generally considered a realistic (if not an overestimate) of realistic transaction costs. For the trend-following strategies, we find that the average breakeven transaction costs are negative for all series, however all of the average breakeven transaction costs for the mean reversion rules are positive, and highest for the FTSE4Good Europe with a magnitude of 30 basis points. However these are just averages across all rules and dont pinpoint how many successful rules there are. Therefore we also study the percentage of rules that generate breakeven transaction costs greater than 50 basis points and we find a number of rules generate breakeven transaction costs greater than 50 basis points. Specially, $0.00 \%, 2.11 \%$ and $7.56 \%$ of trend-following rules generate rules with breakeven transaction costs greater than 50 basis points, while $7.71 \%, 8.87 \%$ and $10.80 \%$ of mean-reversion rules generate breakeven transaction costs greater than 50 basis points. Therefore a good proportion of mean-reversion technical trading rules do generate returns higher than expected transaction costs.

\subsubsection{Data-Snooping}

We also control for data snooping by employing a number of multiple hypothesis procedures to control for the fact that many different rules have been examined. Table 7 presents the percentage of technical trading rules report significant returns after the implement of the bootstrapped procedure of Politis and Romano (1994) and then the four different multiple hypothesis adjustments are applied. We find that all of the adjustments provide the same results indicating that there is no 
difference whether we apply the Bonferroni, Holm, BH or BY adjustments. ${ }^{17}$ We find that there are no significant returns from trend following technical trading rules for the FTSE4Good US, FTSE4Good UK and FTSE4Good Europe. However there are a small proportion of mean reverting technical trading rules that still generate significant returns, with over $8 \%$ of rules generating significant returns in the FTSE4Good US. This suggests that a proportion of the mean-reversion technical trading rules returns are not due to data-snooping but are actually positive, significant returns after accounting for multiple hypothesis testing. Therefore we show that even after the implementation of Politis and Romano (1994) stationary bootstrap procedure and adjusting for multiple hypothesis testing, we find that some mean reverting rules do still produce significant returns.

\subsubsection{Out-Of-Sample Performance}

Another issue with any trading strategy is the in- and out-of-sample performance, which involves examining whether the best performing strategy in the in-sample period still outperforms in the out-of-sample period. This is very important for any investment strategy but notably for any examination of technical trading rules, as Menkhoff (2007) notes that the predictability of technical trading rules have diminished over time. Therefore we provide evidence of the type of performance that could be obtained over an out-of-sample period from 1st January 2013 to 31st December 2017, where our in-sample period is the 1st January 2002 to 31st December 2012. ${ }^{18}$ Therefore we select rules are offer significant returns in the in-sample period up to 31st December 2012 and examine how these rules perform over the ensuing period until the end of the sample on 31st December 2017. Table 8 reports the best rules for each family of rules during the in-sample period, where we select the rules with the highest significant mean return. No trend-following rule generates significant returns in the in-sample period for the FTSE4Good US or FTSE4Good UK. However we do find that the best RSI rule during the in-sample period is a RSI 2-55-45-1 for the FTSE4Good US, and RSI 2-55-35-1 for the FTSE4Good UK. For the FTSE4Good Europe, we

\footnotetext{
${ }^{17}$ This is due to the right-tailed distribution the $p$-values and the fact that very few rules have bootstrapped $p$-values that are on the $5 \%$ level of significance boundary.

${ }^{18}$ This out-of-sample period was chosen arbitrarily as there is no ideal way of selecting the out-of-sample period. Other out-of-sample periods were chosen (such as 1st January 2010 and 1st January 2014) but the results are qualitatively very similar. However these additional results are available upon request from the corresponding author.
} 
find significant returns from MA, EMA, RSI and BB rules.

After identifying the best performing rules in the in-sample period, Table 9 presents the out-ofsample performance of these rules during the out-of-sample period 1st January 2013-31st December 2017. We report the annualized return and the annualized Sharpe ratio for each rule and show that for the FTSE4Goood US that the significant RSI and BB rules in the in-sample period both generate positive annualized returns in the out-of-sample period of $0.47 \%$ and $0.31 \%$ respectively, as well as positive annualized Sharpe ratios. ${ }^{19}$ However the best in-sample RSI rule for the FTSE4Good UK generates a negative out-of-sample annualized return of $-0.31 \%$ and a corresponding negative annualized Sharpe ratio. Nevertheless, the best BB rule in the out-of-sample period generates an annualized return of $0.04 \%$ and annualized Sharpe ratio of 0.05. The FTSE4Good Europe found that four of the rules generated significant returns in the in-sample period and show that three out of four of these generate positive out-of-sample annualized returns up to $0.34 \%$. Only the significant EMA rule in the in-sample period generates out-of-sample returns that are negative. Therefore our out-of-sample results show that the best rules in the in-sample period generate positive returns in the out-of-sample period for six of the eight rules examined.

\section{Conclusions}

Technical trading rules have a long history in financial markets and academia, however there has been a surge in studies examining the performance of them since the seminal study by Brock et al. (1992). Many studies have examined the performance of technical trading rules in stock markets, commodity markets, futures markets, foreign exchange markets and even cryptocurrency markets. However to our knowledge, there is no study that examines how technical trading rules perform when applied to SRI. Therefore this paper examines whether SRI investors should consider employing technical trading rules in their investment strategy. However unlike previous studies, we separate technical trading rules into two distinct categories, namely trend-following and meanreversion rules. These two categories group rules based on their aim, as trend-following strategies aim to follow the trend of the market while mean-reversion rules aim to provide early indication of a reversal in the market. Therefore they each capture completely different aspects of price behavior and therefore need to be examined separately.

\footnotetext{
${ }^{19}$ The other performance measures previously employed in this study are available upon request from the corresponding author.
} 
We find that trend-following and mean-reversion technical trading rules offer quite different performance to investors on SRI. Specifically, we find that trend-following rules offer very little predictive power or positive returns to investors after studying the most popular trend-following technical trading rules. However studying mean-reverting technical trading rules, we find evidence of significant returns for investors, which also generate positive Sharpe, Sortino and Calmar ratios. We find that some of the significant mean-reverting technical trading rules are also significant after implementing the bootstrap procedure of Sullivan et al. (1999) and employing a number of multiple hypothesis adjustment procedures, as suggested by Harvey and Liu (2014). Therefore we find that no trend-following rule offers significant predictive power after accounting for multiple hypothesis testing, but a number of mean-reversion rules do, indicating that SRI investors could implement these rules to generate significant returns. We also implement an in- and out-of-sample procedure to further guard against our results being due to data-mining. We select the best performing rules in the in-sample period and determine how these rules performed in the out-of-sample period. We find that the mean-reversion technical trading rules that generate significant returns in the in-sample period also generate positive returns in the out-of-sample period, indicating that our results are not due to data-mining.

Therefore to conclude, we find that SRI investors should be interested in employing active technical trading rules into their investment strategy. Specifically, they should employ technical trading rules that aim to identify potential changes in market direction rather than traditional trend-following rules as these rules can generate significant returns that are not due to datasnooping or data-mining. 


\section{Bibliography}

Ammann, M., C. Bauer, S. Fischer, and P. Muller (2018). The impact of the morningstar sustainability rating on mutual fund flows. European Financial Management (In Press).

Bajgrowicz, P. and O. Scaillet (2012). Technical trading revisited: False discoveries, persistence tests, and transaction costs. Journal of Financial Economics 106, 473-491.

Batten, J. A., B. M. Lucey, F. McGroarty, M. Peat, and A. Urquhart (2018). Does intraday technical trading have predictive power in precious metal markets? Journal of International Financial Markets, Institutions and Money 52, 102-113.

Bauer, R., J. Derwall, and R. Otten (2007, Jan). The ethical mutual fund performance debate: New evidence from canada. Journal of Business Ethics 70(2), 111-124.

Bauer, R., K. Koedijk, and R. Otten (2005). International evidence on ethical mutual fund performance and investment style. Journal of Banking and Finance 29(7), 1751-1767.

Belghitar, Y., E. Clark, and N. Deshmukh (2014). Does it pay to be ethical? evidence from the ftse4good. Journal of Banking and Finance 47, 54-62.

Bello, Z. Y. (2005). Socially responsible investing and portfolio diversification. Journal of Financial Research 28(1), 41-57.

Benjamini, Y. and Y. Hochberg (1995). Controlling the false discovery rate: A practical and powerful approach to multiple testing. Journal of the Royal Statistical Society, Series B 57, 289-300.

Benjamini, Y. and D. Yekutieli (2001). The control of the false discovery rate in multiple testing under dependency. Annals of Statistics 29, 1165-1188.

Benson, K. L., T. J. Brailsford, and J. E. Humphrey (2006). Do socially responsible fund managers really invest differently? Journal of Business Ethics 65(4), 337.

Bessembinder, H. and K. Chan (1998). Market efficiency and the returns to technical analysis. financial management. Financial Management 27, 5-17.

Bollinger, J. (2002). Bollinger on Bollinger Bands. McGraw Hill, New York. 
Brock, W., J. Lakonishok, and B. LeBaron (1992). Simple technical trading rules and the stochastic properties of stock returns. Journal of Finance 47, 1731-1764.

Brooks, C. and I. Oikonomou (2018). The effects of environmental, social and governance disclosures and performance on firm value: A review of the literature in accounting and finance. British Accounting Review 50, 1-15.

Brzeszczyński, J. and G. McIntosh (2014). Performance of portfolios composed of British SRI stocks. Journal of Business Ethics 120(3), 335-362.

Cellier, A., , P. Chollet, and G. JF. (2016). Do investors trade around social rating announcements? European Financial Management 22(3), 484-515.

Chan, P. T. and T. Walter (2014). Investment performance of environmentally friendly firms and their initial public offers ad seasoned equity offers. Journal of Banking and Finance 44, 177-188.

Chordia, T., A. Goyal, and A. Saretto (2018). p-hacking. SSRN Available at: https://ssrn.com/abstract=3017677, 32-36.

Climent, F. and P. Soriano (2011). Green and good? the investment performance of us environmental mutual funds. Journal of Business Ethics 103(2), 275-287.

Consolandi, C., A. Jaiswal-Dale, E. Poggiani, and A. Vercelli (2009). Global standards and ethical stock indexes: The case of the dow jones sustainability stoxx index. Journal of Business Ethics 87(1), 185-197.

Cummings, L. S. (2000). The financial performance of ethical investment trusts: An australian perspective. Journal of Business Ethics 25(1), 79-92.

Derwall, J. and K. Koedijk (2009). Socially responsible fixed-income funds. Journal of Business Finance and Accounting 36(12), 210-229.

Fanelli, D. (2012). Negative results are disappearing from most disciplines and countries. Scientometrics 90, 891904.

Fernandez-Izquierdo, A. and J. C. Matallin-Saez (2008). Performance of ethical mutual funds in spain: Sacrifice or premium? Journal of Business Ethics 81(2), 247-260. 
Gil-Bazo, J., P. Ruiz-Verdú, and A. A. P. Santos (2010). The performance of socially responsible mutual funds: The role of fees and management companies. Journal of Business Ethics 94(2), 243-263.

Gregory, A. and J. Whittaker (2008). Performance and performance persistence of ethical unit trusts in the UK. Journal of Business Finance \& Accounting 34(7-8), 1327-1344.

Han, Y., T. Hu, and K. Yang (2016). Are there exploitable trends in commodity futures prices? Journal of Banking and Finance 70, 214234.

Han, Y., K. Yang, and G. Zhou (2013). A new anomaly: The cross-sectional profitability of technical analysis. Journal of Financial and Quantitative Analysis 48, 1433-1461.

Harvey, C. R. and Y. Liu (2014). Evaluating trading strategies. The Journal of Portfolio Management 40, 108-118.

Hsu, P.-H., Y. Hsu, and C. Kuan (2010). Testing the predictive ability of technical analysis using a new stepwise test without data snooping bias. Journal of Empirical Finance 17, 471-484.

Hsu, P.-H., M. P. Taylor, and Z. Wang (2016). Technical trading: Is it still beating the foreign exchange market? Journal of International Economics 102, 188-208.

Humphrey, J. E. and D. T. Tan (2014). Does it really hurt to be responsible? Journal of Business Ethics 122, 375386.

Humphrey, J. E., G. J. Warren, and J. Boon (2016). What is different about socially responsible funds? a holdings-based analysis. Journal of Business Ethics 138, 263277.

Jones, S., S. van der Laan, G. Frost, and J. Loftus (2008). The investment performance of socially responsible investment funds in australia. Journal of Business Ethics 80(2), 181-203.

Kempf, A. and P. Osthoff (2007). The effect of socially responsible investing on financial performance. European Financial Management 13, 908-922.

Kempf, A. and P. Osthoff (2008). SRI funds: Nomen est Omen. Journal of Business Finance \& Accounting 35(9-10), 1276-1294.

Kim, J.-B., B. Li, and Z. Liu (2018). Does social performance influence breadth of ownership? Journal of Business Finance $\&$ Accounting Forthcoming. 
Kreander, N., R. H. Gray, D. M. Power, and C. D. Sinclair (2005). Evaluating the performance of ethical and non-ethical funds: A matched pair analysis. Journal of Business Finance and Accounting 32, 1465-1493.

Leite, P. and M. C. Cortez (2015). Performance of european socially responsible funds during market crises: Evidence from france. International Review of Financial Analysis 40, 132 - 141.

Menkhoff, L. (2007). The obstinate passion of foreign exchange professionals: technical analysis. European Journal of Finance 145, 936-972.

Muñoz, F., M. Vargas, and I. Marco (2014). Environmental mutual funds: Financial performance and managerial abilities. Journal of Business Ethics 124(4), 551-569.

Narayan, P. K., S. Mishra, N. S., and K. Thuraisamy (2015). Is exchange rate trading profitable? Journal of International Financial Markets, Institutions and Money 38, 217-229.

Neely, C. J., D. E. Rapach, J. Tu, and G. Zhou (2014). Forecasting the equity risk premium: The role of technical indicators. Management Science 60, 17721791.

Neely, C. J., P. Weller, and R. Dittmar (1997). Is technical analysis in the foreign exchange market profitable? a genetic programming approach. Journal of Financial and Quantitative Analysis 32, 405-426.

Neely, C. J., P. Weller, and J. M. Ulrich (2009). The adaptive markets hypothesis: Evidence from the foreign exchange market. Journal of Financial and Quantitative Analysis 44, 467-488.

Nofsinger, J. and A. Varma (2014). Socially responsible funds and market crises. Journal of Banking and Finance 48, 180-193.

Oikonomou, I., E. Platanakis, and C. Sutcliffe (2018). Socially responsible investment portfolios: Does the optimization process matter? British Accounting Review 50, 379-401.

Ooi, E. and P. Lajbcygier (2013). Virtue remains after removing sin: Finding skill amongst socially responsible investment managers. Journal of Business Ethics 113(2), 199-224.

Park, C. and S. H. Irwin (2007). What do we know about the profitability of technical analysis. Journal of Economic Surveys 121, 786-826. 
Politis, D. and J. Romano (1994). The stationary bootstrap. Journal of the American Statistical Association 89, 1303-1313.

Psaradellis, I., J. Laws, A. A. Pantelous, and G. Sermpinis (2017). Performance of technical trading rules: Evidence from the crude oil market. Available at SSRN: https://ssrn.com/abstract=2832600.

Qi, M. and Y. Wu (2006). Technical trading-rule profitability, data snooping, and reality check: evidence from the foreign exchange market. Journal of Money, Credit and Banking 30, 21352158.

Schroder, M. (2007). Is there a difference? The performance characteristics of SRI equity indices. Journal of Business Finance and Accounting 34(1), 331348.

Shynkevich, A. (2012). Performance of technical analysis in growth and small cap segments of the US equity market. Journal of Banking and Finance 36, 193-208.

Shynkevich, A. (2016). Predictability in bond returns using technical trading rules. Journal of Banking and Finance 70, 55-69.

Smith, D. M., N. Wang, Y. Wang, and E. J. Zychowicz (2016). Sentiment and the effectiveness of technical analysis: Evidence from the hedge fund industry. Journal of Financial and Quantitative Analysis 51, 1991-2013.

Statman, M. (2006). Socially responsible indexes. Journal of Portfolio Management 32, 100-109.

Statman, M. and D. Glushkov (2009). The wages of social responsibility. Financial Analyst Journal 65, 33-46.

Sullivan, R., A. Timmermann, and H. White (1999). Data-snooping, technical trading rule performance, and the bootstrap. Journal of Finance 354, 1647-1691.

Szakmary, A. C., Q. Shen, and S. C. Sharma (2010). Trend-following trading strategies in commodity futures: a re-examination. Journal of Banking and Finance 34, 409-426.

Taylor, M. P. and H. Allen (1992). The use of technical analysis in the foreign exchange market. Journal of International Money and Finance 11, 304-314. 
Timmermann, A. and C. W. J. Granger (2004). Efficient market theory and forecasting. International Journal of Forecasting 50, 15-27.

White, H. (2000). A reality check for data snooping. Econometrica 65, 1097-1126.

Wilder, J. W. (1978). New concepts in technical trading systems. Trend Research, 21-23.

Zarrabi, N., S. Snaith, and J. Coakley (2017). Fx technical trading rules can be profitable sometimes! International Review of Financial Analysis 49, 113-127. 
Table 1: Descriptive statistics of daily returns of the FTSE4GOOD indices employed in this study.

\begin{tabular}{cccc}
\hline & FTSE4Good US & FTSE4Good UK & FTSE4Good Europe \\
\hline Mean & 0.0003 & 0.0002 & 0.0001 \\
SD & 0.0119 & 0.0114 & 0.0125 \\
Max & 0.1213 & 0.0923 & 0.0967 \\
Min & -0.0899 & -0.0852 & -0.0788 \\
Skewness & 0.1076 & 0.0255 & 0.0345 \\
Kurtosis & 10.3118 & 7.2509 & 6.3406 \\
\hline
\end{tabular}


Table 2: The average results generated from all technical trading rules. "No.Buys" and "No.Sells" denotes the average number of buy and sell signals generated, while "Ann.Return" refers to the average annualized return of each trading rule. "Ann. Sharpe" refers to the average annualized Sharpe ratio while "Ann. Sortino" refers to the average annualized Sortino ratio. Finally, "Calmar" refers to the average Calmar ratio.

\begin{tabular}{cccc}
\hline & FTSE4Good US & FTSE4Good UK & FTSE4Good Europe \\
\hline No.Buys & 1097.75 & 1043.41 & 1071.39 \\
No.Sells & 626.66 & 664.56 & 676.30 \\
Ann. Return & $-0.0922 \%$ & $-0.1527 \%$ & $-0.1033 \%$ \\
Ann. Sharpe & -0.2596 & -0.3284 & -0.2478 \\
Ann. Sortino & -0.1427 & -0.2186 & -0.1501 \\
Calmar & -0.0203 & -0.0416 & -0.0280 \\
\hline
\end{tabular}


Table 3: This table reports the percentage number of technical trading rules that generate a positive return, a significant positive return, and positive Sharpe ratios. Note: since a positive Sharpe ratio will also infer a positive Sortino and Calmar ratio, they are omitted from this table.

\begin{tabular}{cccc}
\hline & \% Positive Returns & \% Significant Returns & $\%$ Positive Sharpe \\
\hline FTSE4Good US & $30.44 \%$ & $3.03 \%$ & $21.30 \%$ \\
FTSE4Good UK & $16.79 \%$ & $1.71 \%$ & $10.15 \%$ \\
FTSE4Good Europe & $29.71 \%$ & $1.71 \%$ & $20.83 \%$ \\
\hline
\end{tabular}


Table 4: The average results generated from trend following rules in Panel A, and mean reversion rules in Panel B. "No.Buys" and "No.Sells" denotes the average number of buy and sell signals generated, while while "Ann.Return" refers to the average annualized return of each trading rule. "Ann. Sharpe" refers to the average annualized Sharpe ratio while "Ann. Sortino" refers to the average annualized Sortino ratio. Finally, "Calmar" refers to the average Calmar ratio.

\begin{tabular}{cccc}
\hline & FTSE4Good US & FTSE4Good UK & FTSE4Good Europe \\
\hline Panel A: Trend-Following Rules & & & \\
No.Buys & 1174.57 & 1124.14 & 1148.83 \\
No.Sells & 637.04 & 692.67 & 699.72 \\
Ann. Return & $-0.1242 \%$ & $-0.1856 \%$ & $-0.1304 \%$ \\
Ann. Sharpe & -0.3044 & -0.3710 & -0.2807 \\
Ann. Sortino & -0.1742 & -0.2507 & -0.1749 \\
Calmar & -0.0475 & -0.0607 & -0.0450 \\
No.Buys & & & \\
No.Sells & 664.19 & 604.41 & 638.85 \\
Ann. Return & 568.07 & 511.68 & 545.51 \\
Ann. Sharpe & $0.0886 \%$ & $0.0265 \%$ & $0.0480 \%$ \\
Ann. Sortino & -0.0066 & -0.0963 & -0.0639 \\
Calmar & 0.0350 & -0.0436 & -0.0115 \\
& 0.1196 & 0.0622 & 0.0671 \\
\hline
\end{tabular}


Table 5: This table reports the percentage number of technical trading rules that generate a positive return, a significant positive return, and positive Sharpe ratios for trend following rules in Panel A, and mean reversion rules in Panel B. Note: since a positive Sharpe ratio will also infer a positive Sortino and Calmar ratio, they are omitted from this table.

\begin{tabular}{cccc}
\hline & \% Positive Returns & \% Significant Returns & \% Positive Sharpe \\
\hline Panel A: Trend-Following Rules & & & \\
FTSE4Good US & $23.72 \%$ & $0.00 \%$ & $15.37 \%$ \\
FTSE4Good UK & $9.51 \%$ & $0.00 \%$ & $3.92 \%$ \\
FTSE4Good Europe & $23.66 \%$ & $0.02 \%$ & $15.25 \%$ \\
\hline Panel B: Mean-Reversion Rules & & & \\
FTSE4Good US & $68.38 \%$ & $20.16 \%$ & $54.76 \%$ \\
FTSE4Good UK & $56.39 \%$ & $10.98 \%$ & $44.05 \%$ \\
FTSE4Good Europe & $63.62 \%$ & $11.16 \%$ & $52.05 \%$ \\
\hline
\end{tabular}


Table 6: This table reports the average number of trades each group of technical trading rule performs, and consequently the average breakeven transaction costs.

\begin{tabular}{cccc}
\hline & No.Trades & Roundtrip Breakeven TCs & $\%$ Rules $>50$ basis points \\
\hline Panel A: Trend-Following Rules & & & $0.00 \%$ \\
FTSE4Good US & 360.69 & -0.002120 & $2.11 \%$ \\
FTSE4Good UK & 356.83 & -0.003507 & $7.56 \%$ \\
FTSE4Good Europe & 359.11 & -0.000594 & $7.71 \%$ \\
\hline Panel B: Mean-Reversion Rules & & & $8.87 \%$ \\
FTSE4Good US & 439.16 & 0.002855 & $10.80 \%$ \\
FTSE4Good UK & 429.24 & 0.001855 & 0.002964 \\
FTSE4Good Europe & 439.15 & & \\
\hline
\end{tabular}


Table 7: This table reports the percentage of bootstrapped p-values that are significant at the $5 \%$ level after employing a number of multiple hypothesis testing adjustments.

\begin{tabular}{ccccc}
\hline & Bonferroni & Holm & BH & BY \\
\hline Panel A: Trend-Following Rules & & & & \\
FTSE4Good US & $0.00 \%$ & $0.00 \%$ & $0.00 \%$ & $0.00 \%$ \\
FTSE4Good UK & $0.00 \%$ & $0.00 \%$ & $0.00 \%$ & $0.00 \%$ \\
FTSE4Good Europe & $0.00 \%$ & $0.00 \%$ & $0.00 \%$ & $0.00 \%$ \\
\hline Panel B: Mean-Reversion Rules & & & & \\
FTSE4Good US & $8.39 \%$ & $8.39 \%$ & $8.39 \%$ & $8.39 \%$ \\
FTSE4Good UK & $1.80 \%$ & $1.80 \%$ & $1.80 \%$ & $1.80 \%$ \\
FTSE4Good Europe & $1.87 \%$ & $1.87 \%$ & $1.87 \%$ & $1.87 \%$ \\
\hline
\end{tabular}


Table 8: This table presents the best in-sample technical trading rule parameters for each technical trading rule according to the statistical significance of the average returns. If a family of technical trading rules do not generate any significant in-sample returns, then no technical trading rule is estimated in the out-of-sample period.

\begin{tabular}{cccc}
\hline & FTSE4Good US & FTSE4Good UK & FTSE4Good Europe \\
\hline Panel A: Trend-Following Rules & - & - & $2-20-200-0.0005-4$ \\
MA & - & - & \\
WMA & - & - & $25-100-0.0005-4$ \\
EMA & - & - & - \\
CB & - & - & - \\
F & - & - & - \\
SR & $2-55-45-1$ & $2-55-35-1$ & - \\
RSI & $2-0.5-1$ & $5-1-1$ & $15-65-20-2$ \\
BB & - & - & $10-1-3$ \\
Aroon & &
\end{tabular}


Table 9: This table presents the out-of-sample results for the best technical trading rule from each family of technical trading rules reported in Table 8. We report the annualized return as well as the annualized Sharpe ratio for each rule.

\begin{tabular}{cccc}
\hline & Rule & Ann. Return & Ann. Sharpe \\
\hline FTSE4Good US & RSI & $0.47 \%$ & 0.6470 \\
& BB & $0.31 \%$ & 0.4040 \\
\hline FTSE4Good UK & RSI & $-0.31 \%$ & -0.4263 \\
& BB & $0.04 \%$ & 0.0474 \\
\hline \multirow{3}{*}{ FTSE4Good Europe } & MA & $0.08 \%$ & 0.2547 \\
& EMA & $-0.55 \%$ & -0.6050 \\
& RSI & $0.34 \%$ & 0.3382 \\
& BB & $0.14 \%$ & 0.2168 \\
\hline
\end{tabular}




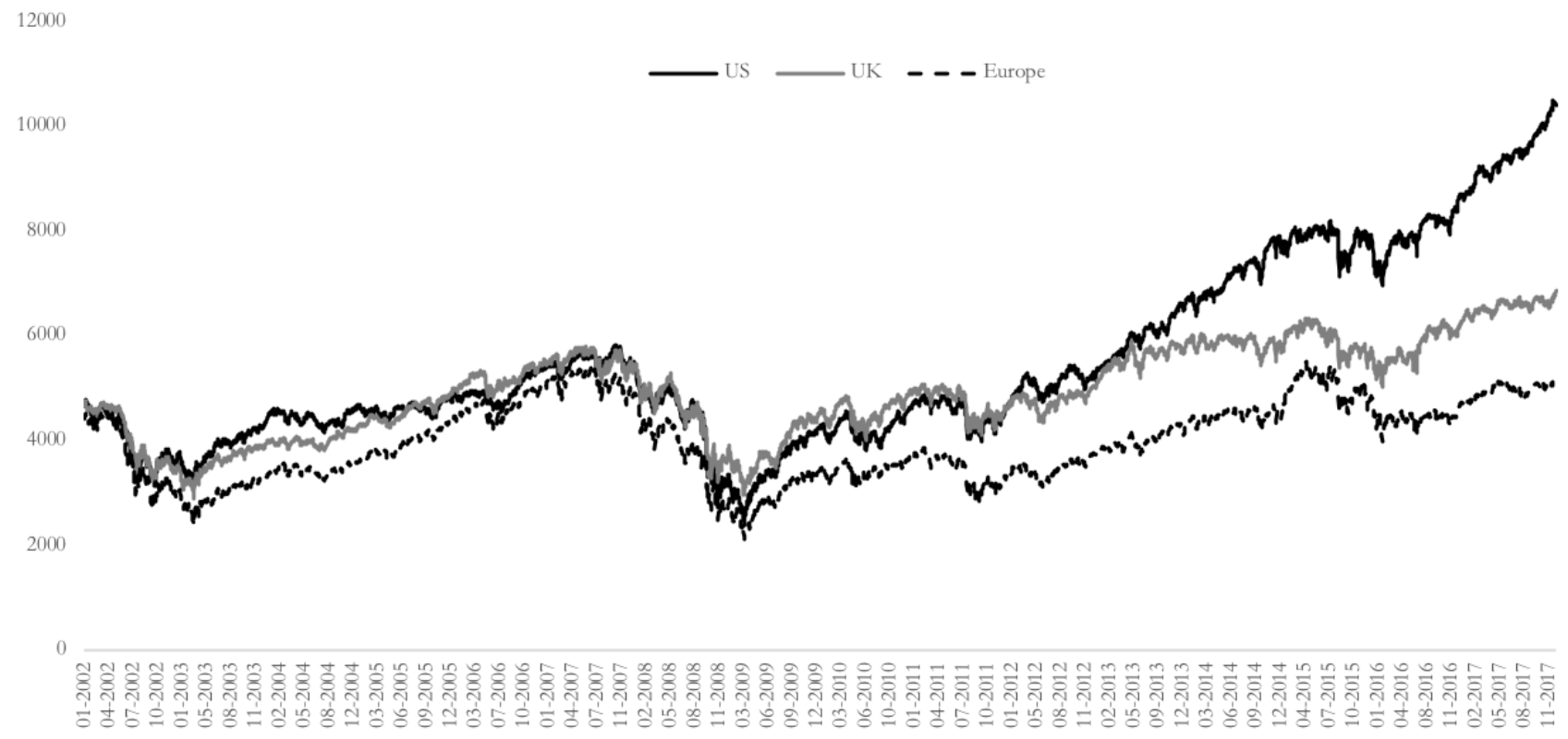

Figure 1: Time-series graphs of the prices of the FTSE4Good indices employed in this study. 


\section{Appendix}

This appendix reports further details on the technical trading rules employed in this study, as well as the parameters of each rule where we braodly follow the class of technical trading rules examined by Hsu et al. (2016)

1. Moving Average Trading Rules

Moving average trading rules are among the most widely used technical trading rules by traders (Taylor and Allen (1992)) and it attempts to ride trends and identify imminent breaks in the trend or the emergence of new trends. For example, the most basic moving average rule is if the current price is larger (smaller) than the average of some number of previous prices, a buy (sell) signal is generated. However traders often replace the current price with a short-term moving average, or state the short-term moving average must be greater than the long-term moving average by a certain percentage, or persist for a certain number of days. We define a simple moving average as:

$$
M A_{t}(j)=\frac{1}{j} \sum_{i=0}^{j-1} s_{t-i}
$$

We study three different moving average rules, namely:

MA1: If the price moves up as least $x$ above $M A_{t}(q)$ and remains so for $d$ periods, go long until its price moves down at least $x$ percent below $M A_{t}(q)$ and remains so for $d$ periods, at which time go short. If the price moves down at least $x$ percent below $M A_{t}(q)$ and remains so for $d$ periods, go short until the price moves up at least $x$ above $M A_{t}(q)$ and remains so for $d$ periods, at which time we go long in the currency.

MA2: If $M A_{t}(p)$ moves up at least $x$ percent above $M A_{t}(q)$ and remains so for $d$ periods, go long until $M A_{t}(p)$ moves down at least $x$ percent below $M A_{t}(q)$ and remains so for $d$ periods, at which time go short. If $M A_{t}(p)$ moves down at least $x$ percent below $M A_{t}(q)$ and remains so for $d$ periods, go short until $M A_{t}(p)$ moves up at least $x$ percent above $M A_{t}(q)$ and remains so for $d$ periods, at which time go long. $p$ is less than $q$.

MA3: If the price moves up at least $x$ percent above any two of $M A_{t}(n), M A_{t}(p)$ and 
$M A_{t}(q)$ and remains so for $d$ periods, go long with one third of the risk budget. If the price moves up at least $x$ percent above all three of $M A_{t}(n), M A_{t}(p)$ and $M A_{t}(q)$ and remains so for $d$ periods, go long with all of the risk budget. If the price moves down at least $x$ percent below any two of $M A_{t}(n), M A_{t}(p)$ and $M A_{t}(q)$ and remains so for $d$ periods, go short with one third of the risk budget. If the price moves down at least $x$ percent below all three of $M A_{t}(n), M A_{t}(p)$ and $M A_{t}(q)$ and remains so for $d$ periods, go short with the whole risk budget. $n$ is less than $p$, which is less than $q$.

We consider a number of different parameter specifications, namely:

$q \in\{2,5,10,15,20,25,50,100,200\}, \# q=9$

$p \in\{2,5,10,15,20,25,50,100,200\}, \# p=9$

$n \in\{2,5,10,15,20,25,50,100,200\}, \# n=9$

$x \in\{0,0.01,0.05,0.1,0.5,1,5\}, \# x=7$

$d \in\{1,2,3,4,5\}, \# d=5$

Therefore, we study the following number of parameterizations per rule:

$M A 1=\# q \times \# x \times \# d=9 \times 7 \times 5=315$

$M A 2=\#(p-q) \times \# x \times \# d=36 \times 7 \times 5=1,260$

$M A 3=\#(n-p-q) \times \# x \times \# d=84 \times 7 \times 5=2,940$

Therefore the total $M A$ rules studied is 7,980 .

2. Exponentially-weighted moving average (EMA) rule

A EMA rule follows the exact same procedure as the SMA rule but more weight is given to more recent observations, and thus the weight of each price change decreases exponentially. The weighting factor in an EMA is based on a smoothing factor generated by the length of the input. The exact same number of rules studied of the SMA are also studied for the EMA, i.e. 7.980 rules.

3. Weighted moving average (WMA) rule

A WMA rule follows the exact same procedure as the SMA rule but more weight is given 
to more recent observations, and thus the weight of each price change decreases in a linear fashion. The exact same number of rules studied of the SMA are also studied for the WMA, i.e. 7.980 rules.

\section{Channel Breakout Trading Rules}

A channel breakout trading rule generates a channel around the price when the highest price over a previous given period is within a given range of the lowest level over the previous given period so that, there are time-varying support and resistance levels that appear to be drifting together within a certain range. A trading signal is therefore generated when the price penetrates beyond the upper or lower bond of the channel since the rule suggests that once a channel is breached, there will be sustained movement in the same direction. A c\% trading channel is defined as occurring when the high level of the price over the previous $j$ periods is within $\mathrm{c} \%$ of the low over the previous $j$ periods so that there are time-varying support and resistance levels that appear to be drifting together with about c\% or less separation. These time-varying support and resistance levels are the lower and upper bonds where the upper bound at a particular period will be c\% above the low of the previous $j$ periods and the lower bound will be $\mathrm{c} \%$ below the high of the previous $j$ periods. We examine:

CB: If a $c \%$ trading channel exists and if the price moves up at least $x$ percent above the upper bound of the channel and remains so for $d$ periods, go long. If a $c \%$ trading channel exists and if the price moves down at least $x$ percent below the lower bound of the channel and remains so for $d$ periods, go short.

We consider a number of different parameter specifications, namely:

$x \in\{0,0.01,0.05,0.1,0.5,1,5\}, \# x=7$

$d \in\{2,3,4,5\}, \# d=4$

$j \in\{2,5,10,25,50,75,100,150,200\}, \# j=9$

$c \in\{0.05,0.01,0.5,0.1,0.25,0.5\}, \# c=6$

Therefore, we study the following number of parameterizations per rule:

$C B=\# x \times \# d \times \# j \times \# c=7 \times 4 \times 9 \times 6=1,512$ 
Therefore the total $C B$ rules studied is 1,512 .

The total number of different technical trading considered are: $7,980+963+630+810+$ $4,536=14,919$

\section{Filter Trading Rules}

The filter rule is one of the first and simplest technical trading rules and follows the basic premise that investors should buy an asset when its price has risen by more than a given percentage above its most recent low, or sell it when the price falls by more than a given percentage below its most recent high. Namely:

F: If the price moves up at least $x$ percent above its most recent low and remain so for $d$ periods, go long. If the price moves down below its most recent high by at least $x$ percent and remains so for $d$ periods, go short. We define the most recent high (low) a the most recent closing price that is greater (less) than the $j$ previous prices, for a given value of $j$.

We consider a number of different parameter specifications, namely:

$x \in\{0,0.01,0.05,0.1,0.5,1,5\}, \# x=7$

$d \in\{1,2,3,4,5\}, \# d=5$

$j \in\{2,5,10,15,20,25,50,100,200\}, \# j=9$

Therefore, we study the following number of parameterizations per rule:

$F=\# x \times \# d \times \# j=7 \times 5 \times 9=315$

Therefore the total $F$ rules studied is 315 .

\section{Support-Resistance Trading Rules}

Support-resistance trading rules generate levels in which the price appears to find difficulty rising beyond (resistance) or difficulty in penetrating (support). The main idea is that a break of either the resistance or support levels will indicate a further movement in the same direction. Therefore they are quite similar to filter rules except a signal is generated when the price moves beyond a support or resistance level by a certain percentage, rather than 
beyond a recent high or low. We define a resistance level as the highest price of the $j$ previous prices and we define a support level as the lowest closing rate of $j$ previous closing and the rule we examine is:

SR: If the price moves up at least $x$ percent above the highest closing of the $j$ previous price and remains so for $d$ periods, go long. If the price moves down at least $x$ percent below the lowest closing of the previous $j$ prices and remains so for $d$ days, go short.

We consider a number of different parameter specifications, namely:

$x \in\{0,0.01,0.05,0.1,0.5,1,5\}, \# x=7$

$d \in\{1,2,3,4,5\}, \# d=5$

$j \in\{2,5,10,15,20,25,50,100,200\}, \# j=9$

Therefore, we study the following number of parameterizations per rule:

$S R=\# x \times \# d \times \# j=7 \times 5 \times 9=315$

Therefore the total $S R$ rules studied is 315 .

\section{Relative Strength Indicator}

A popular type of technical trading rule employed in the foreign exchange market is overbought/oversold indicator, which aims to indicate that the price movement in a particular direction has been too rapid and that a correction is imminent. One of the most popular oscillator rules is the relative strength indicator $(R S I)$ which is:

$$
R S I_{t}(h)=100\left[\frac{U_{t}(h)}{U_{t}(h)+D_{t}(h)}\right]
$$

where $U_{t}(h)$ denotes the cumulated up movement of prices over the previous $h$ periods, and $D_{t}(h)$ denotes the cumulative absolute downward movement over the previous $h$ periods. Therefore the RSI indicator measures the strength of upward movements relative to downward movements and is normalized to lie between 0 and 100. We examine:

RSI: If $R S I_{t}(h)$ moves above $s$ for at least $d$ periods, go short. If $R S I_{t}(h)$ moves below $d$ for at least $d$ periods, go long. 
We consider a number of different parameter specifications, namely:

$h \in\{2,5,10,15,20,25,50,100,200\}, \# h=9$

$s \in\{55,60,65,70,75,80\}, \# s=6$

$b \in\{45,40,35,30,25,20\}, \# b=6$

$d \in\{1,2,3,4,5\}, \# d=4$

Therefore, we study the following number of parameterizations per rule:

$R S I=\# h \times \# s \times \# b \times \# d=9 \times 6 \times 6 \times 5=1620$

Therefore the total $R S I$ rules studied is 1620 .

8. Bollinger Bands

Bollinger Bands were created by John Bollinger in the early 1980s and arose from the need for adaptive trading bands and the observation that volatility was dynamic, not static as was widely believed at the time. The purpose of Bollinger Bands is to provide a relative definition of high and low. By definition prices are high at the upper band and low at the lower band and this definition can aid in rigorous pattern recognition. Bollinger Bands generally include three parameters, with the default settings (Bollinger 2002):

Middle Band $=j-$ day moving averages of prices

Upper Band $=$ middle band $+(p \times S D)$

Lower Band $=$ middle band $-(p \times S D)$

Bollinger (2002) suggests that a window of 20-days captures reasonable intermediate-term price fluctuations and, in statistical terms, the 2 standard deviations should contain about $95 \%$ of the price variations. This means that the price falling outside the bands signals a potential market change. The basic application of Bollinger Bands, namely the volatility breakout method, generates a buy signal when the price closes outside the upper band and a sell signal is generated when the price closes outside the lower band. We examine:

BB: If the price is greater than the upper band for at least $d$ periods, we go long and if 
the price is below the lower band for at least $d$ periods, we go short.

We consider a number of different parameter specifications, namely:

$j \in\{2,5,10,15,20,25,50,100,200\}, \# j=9$

$s d \in\{0.5,1,1.5,2,2.5,3\}, \# s d=6$

$d \in\{1,2,3,4,5\}, \# d=5$

Therefore, we study the following number of parameterizations per rule:

$B B=\# j \times \# s d \times \# d=9 \times 6 \times 5=270$

Therefore the total $B B$ rules studied is 270 .

\section{Aroon Indicator}

The Aroon indictor, proposed by Tushar Change in 1995, is a technical trading rule used for identifying trends and the likelihood that the trend will reverse. It is made up of two lines; the Aroon up which measures the strength of the uptrend and the Aroon down which measures the downtrend. The indicator reports the time it is taking for the price to reach, from a starting point, the highest and lowest points over a given time period, each reported as a percentage of total time. Under this rule a Aroon oscillator is generated which is the difference between the Aroon up and Aroon down. Therefore a positive Aroon oscillator suggests an upward trend while a negative Aroon oscillator indicates a downward trend. Specically,

Aroon: Given a Aroon oscillator exists that looks at $j$ periods, a buy signal is generated if the Aroon indicator is higher than $x$ for at least $d$ periods, while a sell signal is generated if the Aroon indicator is lower than $y$ for at least $d$ periods.

We consider a number of different parameter specifications, namely:

$j \in\{2,5,10,15,20,25,50,100,200\}, \# j=9$

$x \in\{60,65,70,75,80\}, \# x=5$

$y \in\{20,25,30,35,40\}, \# y=5$ 
$d \in\{1,2,3,4,5\}, \# d=5$

Therefore, we study the following number of parameterizations per rule:

$B B=\# j \times \# x \times \# y \times \# d=9 \times 5 \times 5 \times \times 5=1125$

Therefore the total Aroon rules studied is 1125 . 